the charge on ions produced by $\mathrm{X}$-rays and the charge $E$ on a monovalent ion in a liquid are the same. In later investigations in which the ions were produced in various ways, he found that the value of $n$.e for negative ions in gases was in close agreement with the value of $n . E$ for electro. lytic ions.

Further progress in the accurate determination of $e$ was made when $\mathrm{H}$. A. Wilson introduced an important improvement into the method of finding the charge on a drop, whereby it was possible to avoid the uncertainty of dealing with drops with an unknown number of atomic charges. The cloud was formed in the ionised gas by expansion, in an apparatus containing two horizontal parallel electrodes, so that it was possible to establish a vertical field $Z$ in the space where the cloud was formed. A retarding or an accelerating force, $Z$.e, was thus superimposed on the force of gravity $w$ acting on each drop. The weight $w$ of a drop was determined by measuring the velocity when $Z$ was zero and by applying Stokes's formula as in the original method. The charge $e$ was determined by finding the change in the velocity when the force $Z . e$ and $w$ acted together. In this method it was unnecessary to find the number of drops in the cloud. It was observed that the change in the velocity due to the electric force was not the same for each drop, since the cloud appeared to fall in groups of drops with charges in the proportion $1: 2: 3$.

This important observation showed that the charge on a drop, if not equal to, was a multiple of the smallest charge. H. A. Wilson gave $3 \cdot 1 \times 10^{-10}$ as the value of the atomic charge according to this method."

It is well known that the most accurate determinations of the atomic charge were made by Millikan in the period 1909-1916.8 As it was unnecessary to find the number of drops in the cloud in order to determine $e$, Millikan applied
H. A. Wilson's method to single drops. Inaccuracies due to evaporation were avoided by using drops of non-volatile oil, which were placed in electric fields of such strength that they could be made to move against gravity or held in suspension at will. A single drop could thus be kept under observation for long periods. $\mathrm{He}$ tested Stokes's formula, which had been assumed by his predecessors, obtaining an empirical correction to it in the case of small drops, and his very consistent results ${ }^{8}$ showed that the charges carried by drops were always exact multiples of the atomic charge $4 \cdot 77 \times 10^{-10}$ E.S.U.

The earliest investigations of the atomic charge had an important bearing on the interpretation of the experiments made to determine the ratio of the charge $e$ to the mass $m$ of an electron. The first trustworthy determinations of the ratio $\mathrm{e} / \mathrm{m}$ were made in 1897 by Wiechert, ${ }^{9}$ Kaufmann, ${ }^{10}$ and Thomson, ${ }^{11}$ who found that the ratio $e / m$ for cathode rays was about $1 / 2000$ of the ratio $E / M$ of the atomic charge $E$ to the mass $M$ of an atom of hydrogen. It was known from experiments on electrolysis that the ratio $E / M$ was $2.9 \times 10^{14}$ while the best experiments gave $5 \cdot 3 \times 10^{12}$ for the ratio $e / m$, and from the first it was suggested by Wiechert that the charges $E$ and $e$ were equal and consequently that the mass $m$ was about $M / 2000$. This suggestion, however, could only be regarded as a plauisible hypothesis until the identity of the charges $E$ and $e$ had been established in 1899, in relation to which Townsend's investigation of the product n.e ranks in importance with the accurate determination of the atomic charge $e$.

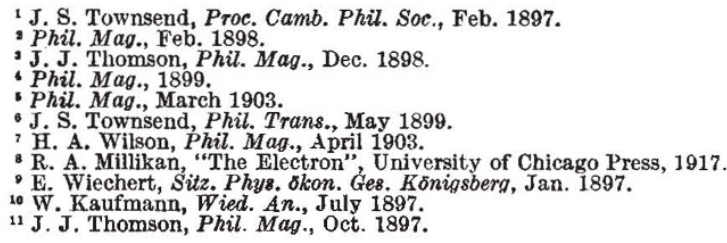

1 J. S. Townsend, Proc. Camb. Phil. Soc., Feb. 1897.

J. J. Thomson, Phil. Mag., Dec. 1898

- Phil. Mag., 1899

Phil. Mag., March 190

J. S. Townsend, Phil. Trans., May 1890.

'R. A. Millikan, "The Electron" University of Chicago Press, 1917.

E. Wiechert, Sitz. Phys. okon. Ges. Konigsberg, Jan. 1897.

${ }^{11}$ J. J. Thomson, Phil. Mag., Oct. 1897.

\title{
Scientific and Industrial Research*
}

$\mathrm{T}$ HE seventeenth annual report of the Department of Scientific and Industrial Research covering the period August 1, 1931-July 31, 1932, appears appropriately as if to punctuate the tributes to the importance of research in our national life which have recently been paid by high authorities in finance. A more impressive picture of the manifold ways in which scientific research is daily applied not merely to the solution of our industrial problems but also to the service of the innumerable needs of a civilised community than is contained in the annual reports of this Department it is difficult to imagine. The present report, including the brief report of the Privy Council, signed by the Right Hon. Stanley Baldwin, and the longer report of the Advisory Council,

* Department of Scientific and Industrial Research. Report for the Year 1931-32. (Cmd. 4254.) Pp. iv + 193, (London: H.M. Stationery Office, 1933.) 38. net. over Lord Rutherford's signature, is no exception to the rule. Lucid as are these reports and the summaries of the work carried out by the National Physical Laboratory, the Chemical Research Laboratory, the research associations, and under the direction of some forty-five research boards and committees, a popular exposition of the matter contained in them should be invaluable propaganda and assist the ordinary citizen to appreciate the magnitude of the contribution thus made to the necessities and luxuries of his daily. life-food and clothing, air and water supply, transport and housing, business and pleasure. Appendices to the report deal with finance, publications and the personnel of the various boards and committees.

There is no department of State in which the beneficial influence of the Department of Scientific and Industrial Research is not felt and no 
proportion of the national income is more profitably spent than that controlled by this Department. It is satisfactory to find that the expenditure detailed in the current report shows only a slight reduction on that recorded in the previous report; the gross expenditure for the year amounted to $£ 695,677$ as compared with $£ 740,520$ in $1930-31$, and the actual expenditure to $£ 534,700$ as against $£ 555,691$. Receipts showed a decrease from $£ 184,829$ to $£ 160,977$, most of which is represented by decreased receipts of the National Physical Laboratory from outside bodies and firms, Government departments, etc. The net expenditure on headquarters administration is $£ 24,900$, grants for research amounted to $\mathfrak{£ 3 4 , 3 9 8}$ net, and to research associations $\mathfrak{1} 82,307$, an increase of $\mathfrak{£} 6,652$ on the previous year. Expenditure on the Geological Survey and Museum amounted to $£ 62,730$, and on the National Physical Laboratory to $£ 200,754$ gross, against which receipts amounted to only $£ 93,982$ instead of $£ 104,706$ in $1930-31$. The net cost of the Chemical Research Laboratory was $£ 19,450$, of radio research $£ 10,482$, of water pollution research $£ 10,796$, fuel research $£ 82,707$, receipts diminishing the gross expenditure on the latter by $£ 6,033$. The major part of the expenditure on food research is met by a grant of $£ 30,502$ from the Empire Marketing Board and this and other receipts bring the gross expenditure of $£ 46,997$ to $£ 11,530$ net. Similarly, receipts amounting to $£ 7,680$ and $\mathfrak{£ 7 , 8 9 6}$ reduce the expenditure on building and forest products research to $£ 34,519$ and $£ 33,792$ respectively.

Nineteen research associations received grants during the year, and the report records that certain of these associations have been able to record a marked increase of industrial support during the past year while others are hopeful of attaining similar success in the near future. The British Electrical and Allied Industries Research Association now derives approximately one-half of its industrial income from supply undertakings, and the majority of lead manufacturers in the country are now members of the British Non-Ferrous Metals Research Association. Refractory material makers are supporting more strongly the British Refractories Research Association, and the voluntary levy scheme launched by the Wool Industries Research Association two years ago is now working smoothly but, mainly owing to bad trade conditions, has not yet shown signs of yielding an income sufficient to meet the Association's present scale of expenditure.

On the other hand, the British Cast Iron Research Association, in spite of the highly important and eminently practical research results to its credit, is experiencing great difficulties in maintaining its industrial income, while membership of the Cutlery Research Association has declined from fifty to ten firms in two years. In view of this lamentable lack of interest in the Association's investigations, the Department concluded that continued expenditure of the public funds at the disposal of the Association was unlikely to lead to results of benefit to the industry as a whole and, with the consequent surrender of these funds, termination of the Association's activities has been inevitably involved.

Reviewing the work of the research associations as a whole, the report emphasises the importance of their work to industries other than those designated by their respective titles and notes movements for widening the basis of industrial support. Few of the research associations appear to be in favour of a compulsory levy scheme, and accordingly the Advisory Council is unprepared at the present time to make representations in favour of introducing a general measure to authorise the compulsory adoption of a levy.

The general interest of the work of the research associations may be illustrated by a few typical examples selected from many to which space forbids even reference. In the iron and steel industry, research has reduced the consumption of coal per ton of finished steel from 31 cwt. in 1924 to 23 cwt. in 1930, representing an estimated average saving on coal used after the pig iron stage of more than $£ 1,468,000$ on the 1930 production. Important work on smoke abatement, refractories, etc., is being carried out in collaboration with other interests concerned. With the support of the water-supply authorities and others, the Non-Ferrous Metals Research Association has commenced a study of the bursting of water-pipes by frost by a thorough investigation of the properties at low temperatures of the materials used for them. The Association is also investigating the quality of galvanised iron with special reference to the corrosion of hot-water tanks and the retention of brightness of polished white metals, such as are used for shop fronts, name plates, etc. These are matters in which the ordinary citizen or householder is as interested as the industrialist, and the same may be said of investigations carried out by the Electrical and Allied Industries Research Association on conducting leads in gas-filled lamps used for office and factory lighting, which have enabled a considerable reduction in the rise of temperature in the fittings to be effected and simultaneously reduced the fire risk. The same Association has developed a simple portable apparatus for determining the conductivity of the ground along a proposed cable route, so that the correct size of cable required to carry the current can be ascertained. Other investigations have been concerned with the efficiency of electrical earthing and on the cause and prevention of interfering noises on telephone lines.

The Refractories Research Association provides a striking example of an association of which the work is of general interest, and closely associated with its investigations are representatives of the Institution of Gas Engineers, the National Federation of Iron and Steel Manufacturers and the British Pottery Manufacturers' Federation. These investigations have ranged over such subjects as the durability of refractory materials and its improvement, the permeability of refractory 
materials to high temperatures and changes in physical structure during the firing of fire clay goods.

The Research Association of the British Paint, Colour and Varnish Manufacturers has continued its investigations on the measurement of the physical and mechanical properties of paint, varnish, and lacquer films, the hiding power of paint, the relations between crystal structure, surface characteristics and pigmentary value. The recently formed Research and Standardisation Committee of the Institution of Automobile Engineers, to which the Department contributes financially, has occupied itself with problems of cylinder and piston wear, lubrication, and with such problems of general interest as silencing, for which a new instrument has been designed.

The Cotton Industry Research Association is not only carrying out important fundamental studies of dyestuff solutions, the dyeing process, and mercerisation, but has also made special efforts to demonstrate to its members the practical value of its operations. More than two thousand visits were paid to mills and works during the year by its liaison staff, and the prestige of the Association is distinctly greater in the trade than a year ago.

The Wool Industries Research Association has been concerned with the various causes of fading such as light and atmosphere, laundering and perspiration, which are often of immediate interest to the public. The Linen Industry Research Association has similarly been concerned with wearing properties under laundering as well as with levelness and regularity of weave. The Launderers' Research Association has been concerned with detergents as well as with the mechanical conditions, with the object of decreasing attrition and the prevention of felting of wool, etc.

Among the problems occupying the attention of the Leather Manufacturers' Research Association have been the deterioration of leather on storage, the factors responsible for dermatitis associated with dyed leather, while the Boot, Shoe and Allied Trades Research Association has designed new lasts on which the contracts for the Army marching boots are being carried out, using vegetable tanned leather curried according to the Association's recommendations. The sound-absorption of rubber flooring in auditoriums, improving the resistance of rubber to oils, ageing, and water absorption are directions in which the Rubber Manufacturers' Research Association is assisting the utilisation of rubber and the revival of this depressed industry.

The Research Association of British Flour Millers is investigating the blending of wheat to give flour of regular and improved qualities. The Research Association for the Cocoa, Chocolate, Sugar, Confectionery and Jam Trades has been concerned with such varied problems as the 'solubility' of cocoa, standardised specifications of purity of materials, including wrappers, coatings of sugar crystal, while the Food Manufacturers' Research Association has carried out successful investigations on the canning of kidneys and liver as well as on the development of satisfactory gums and pastes for labels.

These investigations are, however, only a fraction of those concerned with food with which the Department as a whole has been concerned. The importance of food in the maintenance of health and in the control of disease is being more and more widely recognised in days when emphasis is laid on preventive as against curative methods. It would be difficult to overstress the importance to public health of some of the work which is being carried out to preserve the freshness of food. Merely to enumerate the investigations on the storage of chilled beef, opening up the prospect of chilled beef from Australia being marketed in Great Britain, on the storage of bacon and ham, on canning problems, on the smoke-curing of fish, on the preparation of fish livers for treating pernicious anæmia and on the storage of fruit and vegetables. should bring home to the most unimaginative citizen the value he receives from the expenditure of this insignificant proportion of the national reserve, even if its importance to home industries and to the shipping companies is less apparent.

The importance of the physical and chemical survey of the coal resources of Great Britain has been enhanced by the events of the last two years, and other work carried out under the Fuel Research Board dealing with the scientific utilisation of fuel, including low temperature carbonisation, represents an attack on perhaps the most crucial problem with which the Department is concerned, bearing directly on the uremployment problem as well as, through its reaction on atmospheric pol. lution, on public health.

Again, it is a simple matter for the ordinary citizen to appreciate the immense importance of the work of the Building Research Board outlined in this report, whether as applied to the testing of building materials, the weathering of materials, or the design of reinforced concrete piles for the foundations of big buildings, momentary stresses in which are now being measured by an ingenious application of radio methods. He will readily grasp also the significance of the researches on steel structures now so widely used in building, and the activities of the Radio Research Board, which are frequently as closely related to the needs of the ordinary listener and amateur as to those of the Post Office, the Admiralty, the War Office, the Air Ministry and other bodies at the request of which many of them were originated. The work of the Forest Products Research Board bears directly on the life of timber and the efficiency with which it can be preserved against insect or fungoid attack, whether by the death watch beetle for example or by dry rot, and once again touches many a householder closely.

To do justice to the activities of the National Physical Laboratory might well require volumes, and only a few examples can be given. In the William Froude Laboratory, research on wind resistance has indicated ways in which the air 
resistance of most types of vessel can be reduced by about 30 per cent, while other improvements have been effected in the design of small coaster vessels as well as in the humble barge, the improved design showing on towing tests a 33 per cent improvement in speed for slightly less power. The National Physical Laboratory played an important part in designing the high speed seaplanes which won for Great Britain the 1931 race for the Schneider trophy, as well as in the development of new and safer types of aircraft. Other work assists in the provision of improved materials for industry, including steel and steel alloys capable of with. standing the high temperatures at which modern machinery such as turbines and aircraft engines must work, and workers in other sections of the Laboratory again are investigating the glare effect of different systems of street lighting, the best beams for traffic control signals, the transmission factors of coloured railway signal lights and the lighting of docks, quays and their approaches. It needs little imagination to realise what advance in these fields means not merely to industrial efficiency but even more in the elimination of much suffering and loss of life.

The field covered by the work of the Chemical Research Laboratory is almost equally wide, ranging from products for treatment of sleeping sickness in human beings and in animals, to the preparation of synthetic resins, corrosion research, researches at high pressures, tar research and water pollution. With the latter subject a special board is concerned, and following on the survey of the River Tees recently carried out, one on the River Mersey is now projected.

Space does not permit further reference to many activities of the Department which are of scientific as well as of industrial and general interest. This brief review contains no account of important metallurgical researches for which the Department is responsible, or of its investigations on electrodeposition, lubrication or dental problems. Mention should, however, be made of the Geophysical Survey Research Committee, which has now com. pleted its work and through the activities of which the danger that the development and use of this new applied science in Great Britain would be neglected has been dispelled. Sufficient has been said, however, to demonstrate the unique and invaluable contribution which the Department is making not merely to industrial efficiency but also to industrial development and the public welfare, and to indicate how essential it is in days when economy is the watchword that there should be no restriction of services which have been so productive.

\section{Obituary}

Lieut.-Col. Alfred W. Alcock, c.I.e., F.r.S. WITH the death on March 24 of Alfred Alcock, there has passed away a type of doctor who in the past has so often graced the ranks of the Indian Medical Service-that of the surgeon-naturalist. Zoological science in India has been always enriched by the labours of distinguished medical men, of whom the late Sir Joseph Fayrer and Alfred Alcock may be taken as representing the acme of a period which will never be seen again.

Alfred Alcock was born in Bombay on June 23, 1859. His father, who was a sea captain in the days of windjammers, retired and lived at Blackheath, and there the subject of this memoir went to school and afterwards became a Westminster scholar. In the 'seventies, owing to ruinous losses due to the sudden depreciation of Egyptian Government bonds, he was taken away from school, in 1876, quite unexpectedly. He was then packed off in September of that year to Wynaad in the Malabar District of Southern India, to a coffee plantation, where he had an uncle engaged in this industry. He lived in the jungles of Wynaad and in the neighbouring native State of Cochin, and was able to observe all the operations connected with coffee-planting and also to study the birds and beasts.

As coffee planting was then obviously in the decline, Alcock obtained in September 1877 a post in a newly established firm of commissionagents in Calcutta, and on the voyage from Madras to Calcutta, the ship that carried him, the Duke of Buccleuch, was rammed and almost sunk by a steamer, appropriately named the Vixen. The commission-agent business not proving a success, he next started as a freight-broker on his own account, but soon gave that up to proceed to Chota Nagpur as an assistant to a coolie-recruiting agent, where he remained until February 1880. It is necessary to mention this, as in some ways it proved the turning point of his career, for he met there a young Bengal civilian who lent him Michael Foster's "Primer of Physiology", which cost the sum of one shilling, and this little book proved to him to be what the light of heaven was to St. Paul. It set his face towards natural science, and throughout the rest of his life he thought of Michael Foster (whom he had never met) with the gratitude of a disciple. He next met the Deputy Sanitary Commissioner of Chota Nagpur, Lieut.-Col. J. J. Wood, and this good man took the young Alcock to his heart and hastened him on his way with an old microscope, several timely books and many long talks on botany, natural history and chemistry. This led him to do a little body-snatching on his own in places where the poorer natives disposed of their dead, and from that source he obtained bones to study and began to read Darwin's "Descent of Man" and "Origin of Species". He had now fully resolved to become a medical man.

Alcock next became assistant schoolmaster at a large school for European boys in Darjeeling. 